\title{
86062
}

II. O. Fuchs 1

\section{Approximate Analysis for Optimizing Prestress Treatments}

REFERENCE: Fuchs, H. O., "Approximate Analysis for Optimizing Prestress Treatments," Analytical and Experimental Methods for Residual Stress Effects in Fatigue. ASTM STP 1004, R. L. Champoux, J. H. Underwood, and J. A. Kapp, Eds., American Society for Testing and Materials, Philadelphia. 1988. pp. 13-20.

ABSTRACT: A method of analysis for finding optimum shot peening specifications for given parts and loading conditions is explained. The method is applied to a part with fillets loaded in rotating bending. The computed optimum intensity is $9 \mathrm{C}$. Fatigue tests are reported which compare this intensity to the conventionally specified $7 \mathrm{~A}$. The higher intensity proved clearly superior.

KEY WORDS: shot peening, optimization, crack arrest, stress profiles, fatigue tests

The great improvement in fatigue strength that can be obtained by prestress treatments such as shot peening has been known for about 50 years [1]. When production quantities were large enough to justify the expense of repeated fatigue tests the treatments have been oprimized empirically. For other applications certain rules have been established that recommend or prescribe the treatment, for instance, the specification for shot peening Military Specification for Shot Peening of Metal Parts (MIL-S-13165).

This paper shows a method for finding optimum treatments analytically and reports tests that validated the method by comparing conventional peening to optimized peening, which was four times as heavy as the conventional treatment.

\section{Criteria and Assumptions}

Failures start on the surface in parts that are free of self-equilibrating stresses (called self stresses or residual stresses) and of internal defects. The surface is weaker than the interior because it is exposed to corrosion, it has some roughness, and its particles are not supported by as many neighboring particles as those on the interior. Also, and more importantly, there usually is a stress gradient, with stresses decreasing going from the surface inwards. We neglect the surface weakness and consider only the effects of the stress gradients because shot peening is not very effective in improving fatigue strength in pure axial loading, but is more effective in providing this improvement under the bending and torsion of smooth parts, and surprisingly effective for notches that have high stress gradients.

Producing compressive self stresses in the skin is the main effect of mechanical prestress treatments. We neglect other effects such as changes in structure produced by peening. The compressive stresses in the skin are balanced by tensile stresses in the core. The compressive stresses increase fatigue resistance; the tensile stresses decrease it. Greater peening intensity decreases the risk of fatigue failures that start from the surface and increases the risk of fatigue

${ }^{1}$ Professor, Mechanical Engineering Department, Stanford University, Stanford, CA 94305. 
from the interior is our criterion for optimum peening intensity.

Fatigue failure of a part is expected if the stresses at some point exceed the critical stresses for crack initiation and the resulting crack is not arrested. The critical stress for initiation depends on the material and on the mean stress. The critical stress for crack propagation depends on the threshold stress intensity factor. We assume that factor to be equal to zero ksi in. ${ }^{1 / 2}$ or $\mathrm{MPa} \cdot \mathrm{m}^{1 / 2}$; this is equivalent to assuming that cracks cannot propagate unless the maximum stress is tensile.

To check the stresses at different points against those criteria, we need to know the profiles the distribution in depth of the load stresses and of the self stresses. The load stress profile at fillets is not readily available. We compared the finite element results produced by Tipton [2] with formulas used to arrive at the stress gradient at the surface developed by Siebel and Meuth [3] and developed a formula

$$
L=\left(a x+b x^{n}\right) S
$$

where $S$ is the nominal bending stress at the surface, $L$ is the load stress at point $x, x$ is the distance from the center divided by the radius, and $a, b$ and the exponent $n$ are constants that satisfy the stress concentration at the surface, the gradient at the surface, and the equilibrium with external bending moment.

Figure 1 shows the profile for a $0.035-\mathrm{in} .(0.9-\mathrm{mm})$ fillet radius between the diameters of 1 and $0.8 \mathrm{in}$. (25 and $20 \mathrm{~mm}$ ).

For the self stress profile, we assumed that the maximum self stress produced by peening depends only on the material, not on the intensity, provided the shot is harder than the material. We took the depth of compressive stress and the maximum from data by Brodrick [4], and assumed that the maximum alway; occurs at $25 \%$ of the depth, and that the profile is parabolic for the compressive self stress. We assumed that the tensile self stress is uniformly distributed in

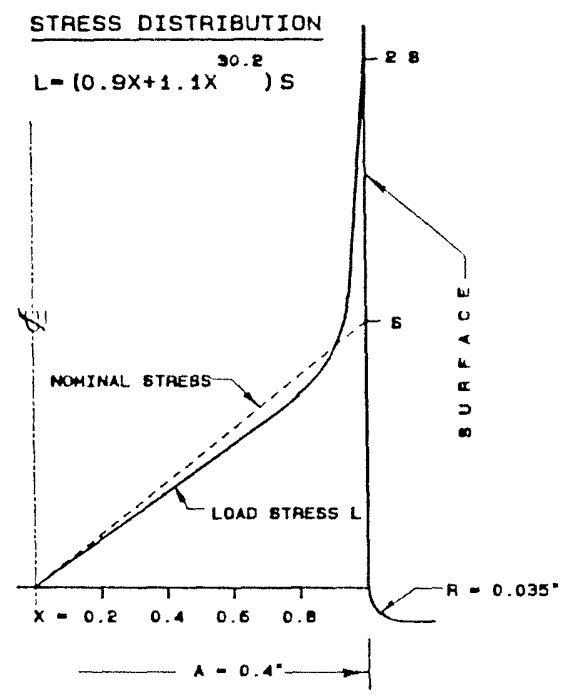

FIG. 1-Profile of load stress at the fillet of the test specimens. 
the core of the round specimen. The concentration of the self stress at the notch [5] was neglected. Figure 2 shows the assumed profile.

We computed the decrease of the near surface self stress caused by yielding in the compressive part of the cycles, but did not change the rest of the profile. We also neglected the redistribution of stresses arising from the growth of circumferential cracks. We considered only the axial stresses; the circumferential and radial stresses below the notch were neglected.

\section{Computation}

The fatigue limit for the specimcn shown in Fig. 3 was calculated for optimum shot peening and for shot peening according to MIL-S-13165. The calculated optinum intensity was $9 \mathrm{C}$, which is more than four times the conventional intensity of $7 \mathrm{~A}$. The calculated fatigue limit with $9 \mathrm{C}$ was $23 \%$ higher than it was with $7 \mathrm{~A}$.

The computations were done on an IBM PC computer. For the given material properties and stress distributions, a bending moment was assumed. Stresses at small increments of depth were computed and compared with faiture criteria. If there was no crack initiation, or if there was crack arrest at a point below the nitiation, the bending moment was increased and the process repeated until a crack was initiated and not arrested. The bending moment previous to this last one was considered the calculated fatigue limit.

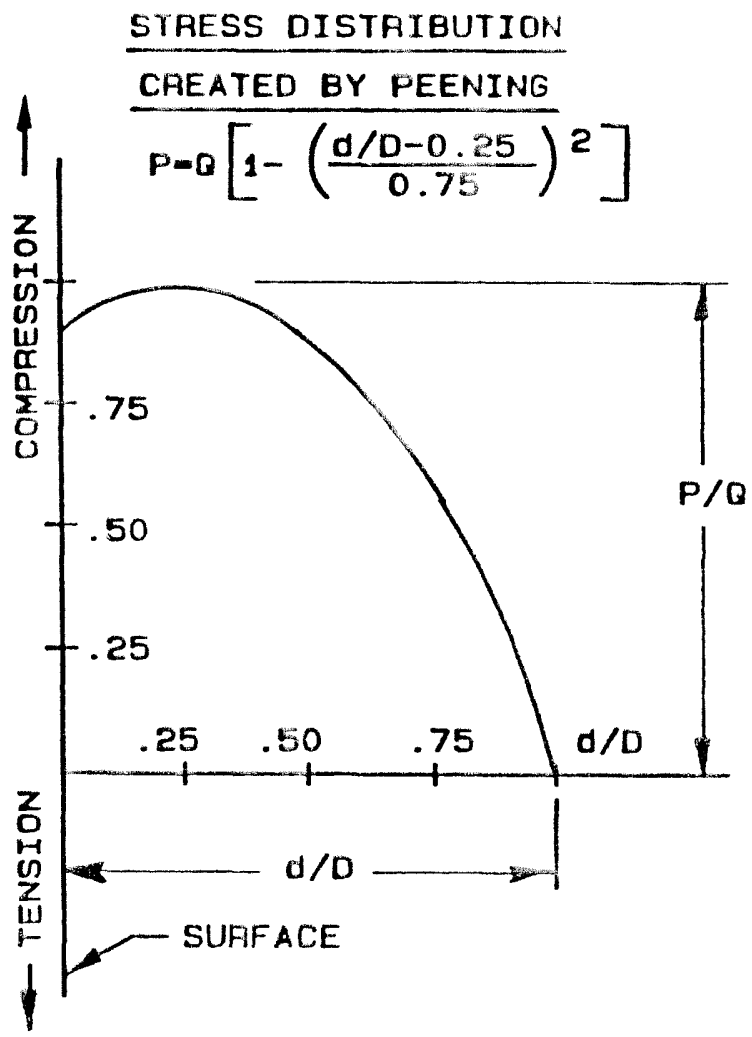

IIG. 2-Profile of self stresses created by peening. 


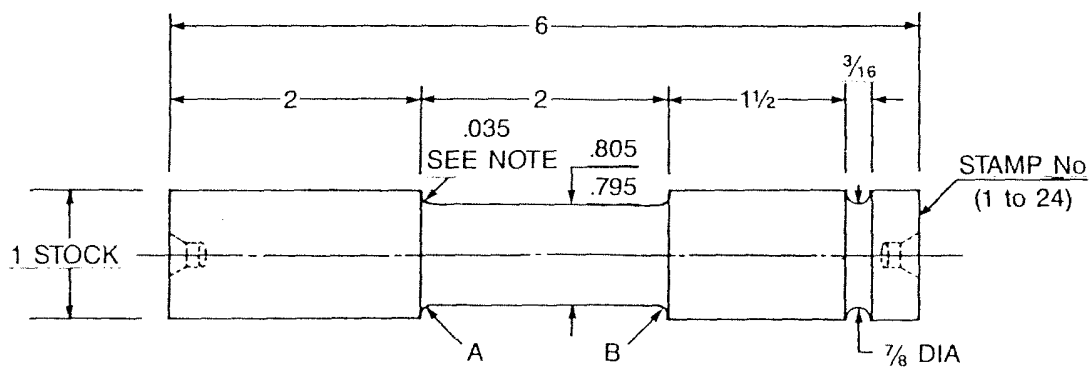

FIG. 3-Peened specimens fatigue tested at lives of about 75,000 cycles; material: 4340 steel; (1) 0.035 radius +0.005 , but radii at $A$ and $B$ must be equal within \pm 0.002 , (2) diameters at $A$ and $B$ must be equal within \pm 0.002: no undercut or step. (3) after finish machining, heat in neutral atmosphere, quench in oil, temper to $\mathrm{R}_{\mathrm{c}}$ 52; do not straighten. (4) shot peen per 86.02.26. (5) check hardness on 1-in. diameter.

The following material properties were used in the calculations:

- cyclic yield strength, $1600 \mathrm{MPa}(230 \mathrm{ksi})$;

- fatigue limit, $556 \mathrm{MPa}(80 \mathrm{ksi})$;

- mean stress coefficient, ${ }^{2}-0.35$; and

- maximum compressive self stress, $883 \mathrm{MPa}(127 \mathrm{ksi})$;

The calculated fatigue limits were

- $334 \mathrm{MPa}(48 \mathrm{ksi})$ with 0.005 in. $(0.13-\mathrm{mm})$ depth of compression (7A intensity) and;

- $410 \mathrm{MPa}(59 \mathrm{ksi})$ with 0.015 in. $(0.38-\mathrm{mm})$ depth of compression (9C intensity).

\section{Experiments}

Fatigue tests were conducted to validate the calculations. They definitely established the greater strength of the fillets peened with the calculated optimum intensity as compared to fillets peened according to MIL-S-13165.

The tests, which are reported here, were only exploratory. They used a few specimens tested at lives of about 75000 cycles to check whether the much greater effort required to establish quantitative data sets would be worth while. Figure 3 is a drawing of the specimens.

These tests were run at Union College, Schenectady, NY, by students of Prof. R. Eisenstadt. They used a rotating beam fatigue machine capable of over $565 \mathrm{~N} \cdot \mathrm{m}(5000 \mathrm{lb}$. in. $)$ in four-point bending. For the first half of the test program, the machine needed frequent adjustments and improvements.

The first series of tests used six discriminating specimens [6]. The two fillets on each specimen are exposed to the same bending moment. One fillet was peened to $7 \mathrm{~A}$, the other to $9 \mathrm{C}$. The stronger fillet would remain unbroken when the weaker fillet failed. To make sure that accidental differences would not confuse the test, all specimens were mounted with the grooved end in the same position in the test machine. Three specimens had high peening intensity in the fillet near the grooved end, the other three had it in the other fillet. This strategy proved especially valuable because of the frequent revisions of the test machine; as both fillets were exposed to the same conditions, the results were conclusive in a qualitative sense, although somewhat doubtful in a quantitative sense. All six specimens failed in the fillet peened to $7 \mathrm{~A}$ intensity, but none failed in the fillet peened to $9 \mathrm{C}$ intensity.

${ }^{2}$ The mean stress coefficient is the slope of the line that plots alternating stress over mean stress at the fatigue limit. 
To obtain a quantitative estimate of the degree of improvement, four more specimens were run in which both fillets had been peened to $9 \mathrm{C}$, and an attempt was made to get approximately the same life to failure.

The raw test data and compured data are shown in Table 1. A visual comparison is shown in Fig. 4. As the tests were run in steps with different bending moments, it was necessary to convert numbers of cycles to accumulated damage cycles. This was done by assuming that the damage cycles $\left(n^{\prime}\right)$ were proportional to the ninth power of the respective bending moments.

Based on the logarithmic means of the bending moments and cumulative damage cycles, the strength improvement was about $4 \%$ at about 70,000 cycles. Based on the weakest of each set of specimens, the strength improvement was about $8 \%$ at about 35000 cycles. In both sets of

TABLE $1-$ Step test results.

\begin{tabular}{|c|c|c|}
\hline$M$ & $n$ & $n^{\prime}$ \\
\hline & 1 & \\
\hline 3499 & 70142 & 11538 \\
\hline 3888 & 71450 & 30353 \\
\hline \multirow[t]{3}{*}{4276} & 66829 & 66829 \\
\hline & & $\overline{108710}=N^{\prime}$ \\
\hline & 2 & \\
\hline 3499 & 67590 & 11118 \\
\hline 3888 & 69594 & 29.564 \\
\hline \multirow[t]{3}{*}{4276} & 61508 & 61508 \\
\hline & & $\overline{102190}=N^{\prime}$ \\
\hline & 3 & \\
\hline 3499 & 69470 & 26884 \\
\hline \multirow[t]{3}{*}{3888} & 16300 & 16300 \\
\hline & & $33184=N^{\prime}$ \\
\hline & 4 & \\
\hline 2916 & 200700 & 7769 \\
\hline 3110 & 6.3870 & $44 ! 4$ \\
\hline 3.304 & 38430 & 4579 \\
\hline $3+499$ & 32700 & 6528 \\
\hline 3693 & 34849 & 11306 \\
\hline 3888 & 35651 & 18380 \\
\hline 4082 & 38500 & 30805 \\
\hline 2527 & 34078 & 364 \\
\hline 2721 & 35803 & 743 \\
\hline 2916 & 34849 & 1349 \\
\hline 3110 & 33026 & 2283 \\
\hline 3304 & 35180 & 4191 \\
\hline 3499 & 73714 & 14748 \\
\hline 3693 & 109000 & 35316 \\
\hline 3888 & 136,600 & 70485 \\
\hline \multirow[t]{3}{*}{4185} & 23574 & 23574 \\
\hline & & $\overline{236834}=N^{\prime}$ \\
\hline & 5 & \\
\hline 3499 & 72881 & 11989 \\
\hline 3888 & 73889 & 31389 \\
\hline 4276 & 27126 & 27126 \\
\hline \multirow[t]{2}{*}{3797} & 13193 & 4529 \\
\hline & & $\overline{75033}=N^{\prime}$ \\
\hline
\end{tabular}


TABLE 1-Continued.

\begin{tabular}{|c|c|c|}
\hline$M$ & $n$ & $n^{\prime}$ \\
\hline & 6 & \\
\hline 3499 & 47228 & 9428 \\
\hline 3888 & 57711 & 29753 \\
\hline \multirow[t]{3}{*}{4185} & 19068 & 19068 \\
\hline & & $58249=N^{\prime}$ \\
\hline & 7 & \\
\hline \multirow[t]{2}{*}{4573} & 35668 & $35668=N$ \\
\hline & 8 & \\
\hline \multirow[t]{2}{*}{4573} & 49379 & $49379=N^{\prime}$ \\
\hline & 9 & \\
\hline \multirow[t]{2}{*}{4185} & 32604 & $32604=N^{\prime}$ \\
\hline & 10 & \\
\hline 4185 & 238600 & 107310 \\
\hline 4573 & 52100 & 52100 \\
\hline 4185 & 16300 & 7335 \\
\hline \multirow[t]{2}{*}{4573} & 55854 & 55854 \\
\hline & & $\overline{222597}$ \\
\hline
\end{tabular}

Nore: $M=$ bending moment (lb. in.), $n=$ number of revolutions, cumulative cycles $n^{\prime}=n\left(M / M_{\max }\right)^{\prime}$.

Note: $\log$ mean for 11 to \#6:

\begin{tabular}{|c|c|c|}
\hline \multirow{7}{*}{$M$} & \multirow[b]{2}{*}{3.631} & \multirow[b]{2}{*}{5.036} \\
\hline & & \\
\hline & 3.631 & 5.009 \\
\hline & 3.590 & 4.521 \\
\hline & 3.622 & 5.374 \\
\hline & 3.631 & 4.875 \\
\hline & 3.622 & 4.765 \\
\hline$(\delta=0.015)$ & $3.621 \quad(\delta=0.287)$ & $\overline{4.930}$ \\
\hline \multicolumn{3}{|c|}{$\begin{array}{l}\text { mean } M=4178 \mathrm{lb} . \text { in } . \\
\text { mean } N^{\prime}=85100 \text { cycles }\end{array}$} \\
\hline \multicolumn{3}{|c|}{$\log$ mean for \#7 to \#10 } \\
\hline$M$ & 3.660 & 4.746 \\
\hline & 3.660 & 4.694 \\
\hline & 3.622 & 4.513 \\
\hline & 3.660 & 5.348 \\
\hline$(\delta=0.019)$ & $\overline{3.651} \quad(\delta=0.362)$ & $\overline{4.825}$ \\
\hline
\end{tabular}

specimens, there was a weak specimen that had the shortest life and also the lowest bending moment at failure.

\section{Discussion}

The mechanism by which compressive self stresses arrest cracks that start from notches ha: been investigated by Heller et al. [7] and by Gerber and Fuchs [8]. They looked at the stres 


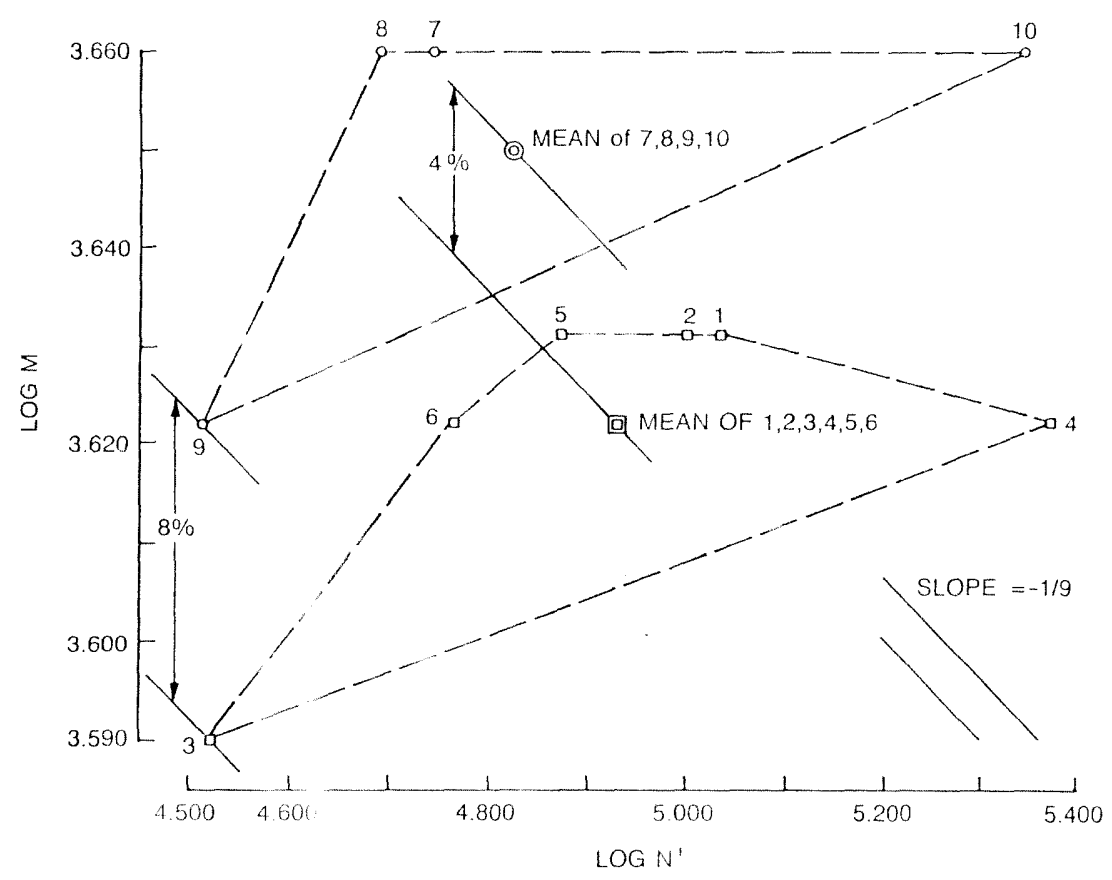

FIG. 4-Fatigue test results.

profile below V-grooves for which approximate solutions had been developed by Neuber [9]. The present work looks at fillets for which no general solutions are known. It simplifies the analysis by neglecting a number of factors. The way in which shot peening raises fatigue strength by arresting cracks at some depth below the surface of smooth bending specimens was shown by Starker et al. [10].

The use of cumulative damage cycles in evaluating the results of stepped fatigue tests requires an assumption about the unknown $\mathrm{S}-\mathrm{N}$ curve. We assumed a fatigue strength exponent equal to -0.11 . This compares with exponents of about -0.09 given in the literature for similar steels. We assumed that the notched, peened part would have a stronger slope than the smooth specimens would. The stronger slope favors the conventionally peened specimens in the comparison.

\section{Conclusion}

A simplified analysis showed that the optimum shot peening intensity for a fillet is more than four times the conventionally specified intensity. Exploratory tests showed that the computed optimum intensity is definitely superior at fatigue lives between 30,000 and 200,000 cycles.

\section{Acknowledgments}

This work was sponsored by the Metal Improvement Company, which provided financial support and advice ahout shot peening. The computer program was developed by Saeed Benaie. The test were carriet out under the supervision of Professor R. Eisenstadt of Union College. The author is grateful for this help. 


\section{References}

[1] Almen, J. O., Residual Stresses and Fatigue in Metals, McGraw-Hill, New York, 1963, p. 64.

[2] Tipton, S. M., Fatigue behavior under multiaxial loading in the presence of a notch, Ph.D. Disserta. tion, Stanford University, Stanford, CA, 1984, p. 134.

[3] Siebel, E. and Meuth, H. O., "Die Wirkung von Kerben bei schwingender Beanspruchung." VDI Zeitschrift, Vol. 91, 1949, pp. 319-323.

[4] Brodrick, R. F., "Protective shot peening of propellers," WADC Technical Report 55-56, Part I, p. 25-36. Also shown in "Shot Peening Applications," Metal Improvement Co., Paramus, N.J., 1980, p. 10.

[5] Todd, R. H. and Fuchs, H. O., "Self stress concentrations," Experimental Mechanics, Vol. 11, 1971, pp. 548-553.

[6] Fuchs, H. O., "Fatigue research with discriminating specimens," Fatigue of Engineering Material and Structures, Vol. 2, 1979, pp. 207-215.

[7] Heller, R. A., Seki, M., and Freudenthal, A. M., "The effects of residual stress on random fatigu life," Proceedings of ASTM, Vol. 64, pp. 516-535.

[8] Gerber, T. L. and Fuchs, H. O., "Improvement in the fatigue strength of notched bars by compressiv self stresses," in Achievement of High Fatigue Resistance in Metal and Alloys STP 467. America Society for Testing and Materials, Philadelphia, 1970, pp. 276-295.

[9] Neuber, H., Kerbspannungslehre, Springer Verlag, Berlin, 1958.

[10] Starker, P., Wohlfahrt, H., and Macherauch, E. "Biegewechselfestigkeit und Groesseneffekt bei us terschiedlich warmbehandelten Stahlproben aus CK 45 nach Kugelstrahlen" Proceedings of the Fir International Conference on Shot Peening, Pergamon, Oxford, 1981, pp. 613-623. 


\section{References}

[1] Almen, J. O., Residual Stresses and Fatil

[2] Tipton, S. M., Fatigue behavior under $\mathrm{m}$ tion, Stanford University, Stanford, CA,

[3] Siebel, E. and Meuth, H. O., "Die Wir Zeitschrift, Vol. 91, 1949, pp. 319-323.

[4] Brodrick, R. F., "Protective shot peenin 25-36. Also shown in "Shot Peening Ap. p. 10.

[5] Todd, R. H. and Fuchs, H. O., "Self stre pp. 548-553.

[6] Fuchs, H. O., "Fatigue research with di and Structures, Vol. 2, 1979, pp. 207-2.

[7] Heller, R. A., Seki, M., and Freudenth: life," Proceedings of ASTM, Vol. 64, pF

[8] Gerber, T. L. and Fuchs, H. O., "Impro' self stresses," in Achievement of High 1 Society for Testing and Materials, Phila

[9] Neuber, H., Kerbspannungslehre, Sprir

[10] Starker, P., Wohlfahrt, H., and Macher terschiedlich warmbehandelten Stahlprc International Conference on Shot Peeni: 